\title{
Unipolar Brush Cells of the Cerebellum Are Produced in the Rhombic Lip and Migrate through Developing White Matter
}

\author{
Chris Englund, ${ }^{1}$ Tom Kowalczyk, ${ }^{1}$ Ray A. M. Daza, ${ }^{1}$ Avner Dagan, ${ }^{1}$ Charmaine Lau, ${ }^{1}$ Matthew F. Rose,${ }^{4}$ and \\ Robert F. Hevner ${ }^{1,2,3}$ \\ ${ }^{1}$ Department of Pathology, ${ }^{2}$ Institute for Stem Cell and Regenerative Medicine, and ${ }^{3}$ Center on Human Development and Disability, University of \\ Washington, Seattle, Washington 98104, and ${ }^{4}$ Program in Developmental Biology, Howard Hughes Medical Institute, Baylor College of Medicine, Houston, \\ Texas 77030
}

Unipolar brush cells (UBCs) are glutamatergic interneurons in the cerebellar cortex and dorsal cochlear nucleus. We studied the development of UBCs, using transcription factor Tbr2/Eomes as a marker for UBCs and their progenitors in embryonic and postnatal mouse cerebellum. Tbr2 ${ }^{+}$UBCs appeared to migrate out of the upper rhombic lip via two cellular streams: a dorsal pathway into developing cerebellar white matter, where the migrating cells dispersed widely before entering the internal granular layer, and a rostral pathway along the cerebellar ventricular zone toward the brainstem. Ablation of the rhombic lip in organotypic slice cultures substantially reduced the production of $\mathrm{Tbr} 2{ }^{+}$UBCs. In coculture experiments, $\mathrm{Tbr} 2{ }^{+} \mathrm{UBCs}$ migrated from rhombic lip explants directly into the developing white matter of adjacent cerebellar slices. The origin of Tbr ${ }^{+}$UBCs was confirmed by colocalization with $\beta$-galactosidase expressed from the Math 1 locus, a molecular marker of rhombic lip lineages. Moreover, the production of Tbr2 ${ }^{+}$UBCs was Math1 dependent, as Tbr2 ${ }^{+}$UBCs were severely reduced in Math1-null cerebellum. In reeler mutant mice, Tbr2 ${ }^{+}$UBCs accumulated near the rhombic lip, consistent with impaired migration through developing white matter. Our results suggest that UBCs arise from the rhombic lip and migrate via novel pathways to their final destinations in the cerebellum and dorsal cochlear nucleus. Our findings support a model of cerebellar neurogenesis, in which glutamatergic and GABAergic neurons are produced from separate progenitor pools located mainly in the rhombic lip and the cerebellar ventricular zone, respectively.

Key words: Eomes; GluR2; Math1; Pax6; reeler; Tbr2

\section{Introduction}

Unipolar brush cells (UBCs) are a unique type of glutamatergic interneuron in the cerebellar cortex and cochlear nuclei (for review, see Kalinichenko and Okhotin, 2005). UBCs were recognized as a distinct neuron type by Altman and Bayer (1977), who called them "pale cells." Later, they were named UBCs by Mugnaini and colleagues, who described their unique morphology, characterized by a single thick dendrite ending in a "brush" of fine dendrioles (Harris et al., 1993; Mugnaini and Floris, 1994). In the cerebellum, UBCs are abundant in regions linked to vestibular functions, especially lobule X (nodulus) and the ventral portion of lobule IX (uvula) in the vermis (Diño et al., 1999). Within the vermis, UBCs are further concentrated in specific parasagittal domains (Diño et al., 1999). Two subtypes of UBCs have been distinguished: one subtype expresses calretinin, the other expresses metabotropic glutamate receptor $1 \alpha(\operatorname{mGluR} 1 \alpha)$

Received Dec. 6, 2005; revised July 14, 2006; accepted Aug. 1, 2006.

This work was supported by National Institutes of Health Grant K02 NS045018 and the Edward Mallinckrodt Jr Foundation. C.E. and T.K. are recipients of Mary Gates Research Scholarships. We gratefully acknowledge Dr. Huda Zoghbi for the gift of Math1-lacZ and Math1-null brains. We thank Drs. J. Mason and D. Price for tau-GFPtransgenic mice.

Correspondence should be addressed to Dr. Robert Hevner, Harborview Medical Center, Box 359791, 325 Ninth Avenue, Seattle, WA 98104. E-mail: rhevner@u.washington.edu.

DOI:10.1523/JNEUROSCI.1610-06.2006

Copyright $\odot 2006$ Society for Neuroscience $\quad$ 0270-6474/06/269184-12\$15.00/0
(Nunzi et al., 2002). Both subtypes express glutamate receptor 2 (GluR2) (Sekerková et al., 2004). Functionally, UBCs amplify inputs from vestibular ganglia and nuclei, by spreading and prolonging excitation within the internal granular layer (Nunzi et al., 2001).

UBCs are produced during the late embryonic period in rodents, but their origins have remained obscure (Sekerková et al., 2004; Ilijic et al., 2005). The cerebellum contains three main progenitor compartments where UBCs might be produced: (1) the cerebellar ventricular zone, source of Purkinje cells and inhibitory interneurons (Maricich and Herrup, 1999; Hoshino et al., 2005); (2) the rhombic lip, source of deep nuclei projection neurons (Machold and Fishell, 2005; Wang et al., 2005; Fink et al., 2006); and (3) the external granular layer, source of granule neurons (Ben-Arie et al., 1997). Because the external granular layer is in turn derived from the rhombic lip, the rhombic lip is the ultimate source of granule neurons as well as deep nuclei projection neurons (Wang et al., 2005). Also, some progenitors from the ventricular zone divide in the developing cerebellar white matter to generate GABAergic interneurons (Zhang and Goldman, 1996). Previous studies have suggested that UBCs may be produced in the external granular layer or the ventricular zone. Abbott and Jacobowitz (1995) proposed that UBCs arise from a "hot spot" of calretinin ${ }^{+}$cells in the external granular layer. In contrast, Ilijic et al. (2005) reasoned that UBCs come from the 


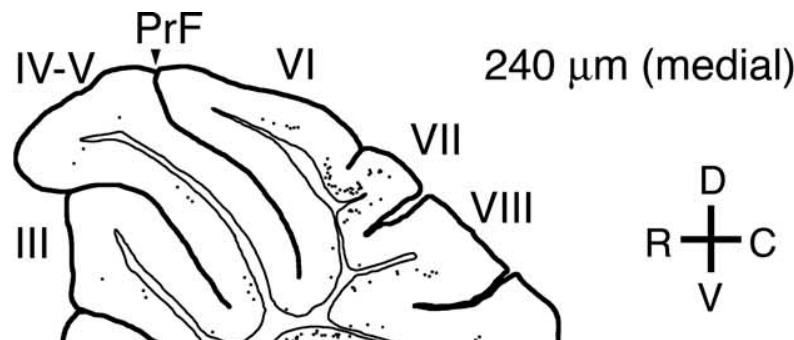

$|-| \mid$
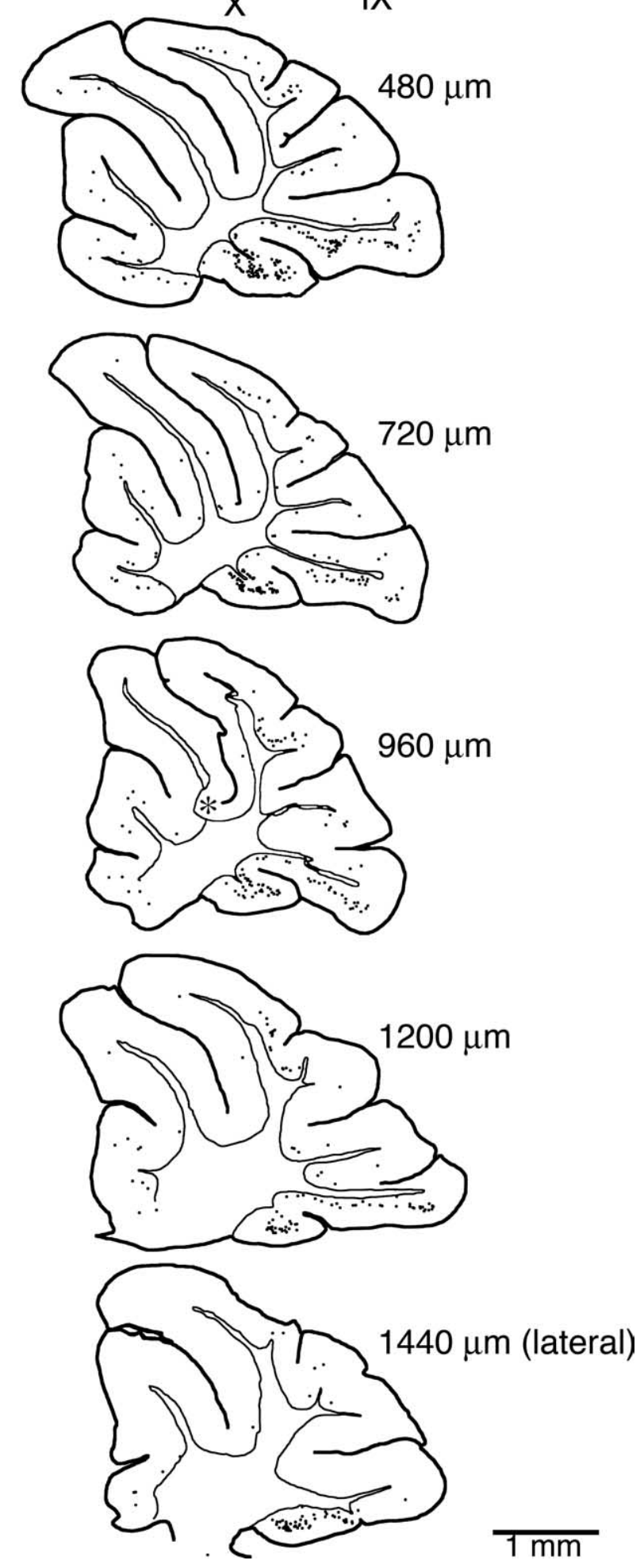

ventricular zone, because many UBCs are positioned ectopically near the ventricular zone in reeler mice. The migration pathways of UBCs, like their origins, have been uncertain.

In the present study, we used Tbr2/Eomes, a T-domain transcription factor (Bulfone et al., 1999), as a marker of cerebellar UBCs and their progenitors throughout development and adulthood. Using Tbr2 to trace their origins, we found that most or all UBCs are produced in the rhombic lip and migrate along novel pathways through the cerebellum. More broadly, our results add to the list of glutamatergic neuron types produced from the rhombic lip. In contrast, GABAergic neurons (Purkinje cells and inhibitory interneurons) are produced mainly from the cerebellar ventricular zone (Hoshino et al., 2005).

\section{Materials and Methods}

Animals and tissue preparation. B6 mice (The Jackson Laboratory, Bar Harbor, ME) were used for most experiments. In addition, reeler mice (B6C3Fe a/a-Reln ${ }^{r l} / \mathrm{J}$; The Jackson Laboratory), tau-GFP transgenic mice (Pratt et al., 2000), and Math1 mutant mice (Mathl ${ }^{\text {lacZ }}$ and Math $1^{-}$) (Wang et al., 2005) were used for some experiments where indicated. The mice were used according to a protocol approved by the Institutional Animal Care and Use Committee at the University of Washington. Anesthesia, perfusion, and killing were done as detailed previously (Hevner et al., 2004) and are described only briefly here. For bromodeoxyuridine (BrdU) labeling, timed-pregnant dams [12:00 P.M. of the plug day, embryonic day 0.5 (E0.5)] were given BrdU by intraperitoneal injection ( 40 $\mathrm{mg} / \mathrm{kg}$ ). For acute BrdU labeling, a single dose of BrdU was given, and the dam was killed 30 min later. For BrdU birthdating, three doses of BrdU were given on the same embryonic day at $4 \mathrm{~h}$ intervals (8:00 A.M., 12:00 P.M., and 4:00 P.M.). For histological studies, embryos were removed and immersion-fixed after Avertin anesthesia of the dam. Neonatal pups were perfused under cryoanesthesia, and older mice were perfused under Avertin anesthesia. The fixative in each case was cold, phosphatebuffered $4 \%$ paraformaldehyde. Brains were removed and further fixed for $16-20 \mathrm{~h}$ at $4^{\circ} \mathrm{C}$, rinsed and cryoprotected with sucrose, and frozen in OCT. Sections were cut at $10-12 \mu \mathrm{m}$, air-dried, and stored at $-80^{\circ} \mathrm{C}$.

Organotypic slice cultures of developing cerebellum. Procedures for slice cultures were adapted from Anderson et al. (1997). B6 mice were mated with tau-GFP heterozygotes to produce litters in which half the embryos were tau-GFP heterozygotes, and half were nontransgenic. A total of 64 embryos were used for slice culture experiments, 6 of which were E13.5, 24 were E14.5, 26 were E16.5, and 8 were E17.5. Embryos from the same litters were used for control, ablation, and coculture experiments. The embryos were harvested from dams under Avertin anesthesia and immediately placed in ice-cold HBSS. The brains were rapidly removed into cold Krebs' buffer. The forebrains were discarded, and midbrainhindbrain blocks were trimmed to include only cerebellum and adjacent brainstem. The tissue blocks were embedded in $4 \%$ low melting point agarose and sliced sagittally or coronally on a vibratome $(300 \mu \mathrm{m})$. Slices were transferred to $13 \mathrm{~mm}$ Nuclepore polycarbonate membranes (Whatman, Ann Arbor, MI) floating on 10\% fetal calf serum-supplemented culture media (DMEM with glutamine and pen/strep; Invitrogen, Carlsbad, CA) in $60 \times 15 \mathrm{~mm}$ Falcon polystyrene center-well organ culture plates (Becton Dickinson, Mountain View, CA), and cultured at the gas/ liquid interface at $37^{\circ} \mathrm{C}$ with $5 \% \mathrm{CO}_{2}$. Control slices were left intact. Slices for ablation experiments were briefly removed from culture wells, placed

$\leftarrow$

Figure 1. Distribution of $\mathrm{Tbr}^{+}$cells in the adult mouse cerebellum (P201). The locations of $\mathrm{Tbr}^{+}$cell nuclei (dots) were mapped by tracing from digital images of sagittal sections. Thick lines indicate the cerebellar surface; thin lines indicate the boundary between cerebellar cortex and white matter. Tbr2 ${ }^{+}$cells were located in the internal granular layer, mainly in lobule X (nodulus) and the ventral part of lobule IX (uvula), with a secondary concentration in lobules $\mathrm{VI}-\mathrm{VII}$. The abundance of $\mathrm{Tbr} 2^{+}$cells was highest near the midline and decreased sharply in the hemispheres. The distance from the midline is shown above each section. Roman numerals indicate lobules of the vermis. The asterisk indicates a tissue fold. Orientation: $C$, caudal; D, dorsal; $R$, rostral; $V$, ventral. Scale bar, $1 \mathrm{~mm}$. 
in a dry plastic culture plate under a dissecting microscope, cut with a scalpel to remove the rhombic lip, and immediately returned to the culture media. For coculture experiments, the rhombic lip was ablated and replaced with an explant of rhombic lip from tau-GFP transgenic slices, prepared from littermate embryos. Slices and explants were matched for mediolateral or rostrocaudal level. The tau-GFP transgenic rhombic lip was placed in the same orientation as the ablated rhombic lip, and cocultures were immediately returned to the media. Slices were further cultured for 2-4 d in serum-free Neurobasal/B27 media (Invitrogen) and then fixed with cold, phosphatebuffered $4 \%$ paraformaldehyde for $1 \mathrm{~h}$. The fixed tissue slices were rinsed with PBS, cryoprotected with sucrose, embedded in OCT, and frozen for cryosectioning.

Immunofluorescence. Cryosections were pretreated for antigen enhancement and BrdU detection, processed with primary and secondary antibodies, and counterstained with $4^{\prime}, 6^{\prime}$ diamidino-2-phenylindole (DAPI) or TOPRO-3 (Invitrogen) as described previously (Hevner et al., 2004). For double immunofluorescence with green fluorescent protein (GFP), the procedure was modified to incorporate sequential immunofluorescence reactions, as follows. Antigen enhancement and $\mathrm{HCl}$ treatment were initially omitted. The first incubation with primary antibodies included only anti-GFP, which was then detected with secondary antibodies. The sections were rinsed with PBS and then fixed with buffered $4 \%$ paraformaldehyde at $4^{\circ} \mathrm{C}$ for $30 \mathrm{~min}$. The sections were again rinsed and then boiled with $10 \mathrm{~mm}$ sodium citrate, $\mathrm{pH}$ 6.0, for antigen enhancement. Tissue was again incubated with blocking solution, followed by a second sequence of primary and secondary antibodies for the desired antigen. Sections were then rinsed, counterstained, and coverslipped as usual.

Primary and secondary antibodies. Mouse monoclonal antibodies included: anti-BrdU (1:200), anti-calretinin (1:1000), and antiproliferating cell nuclear antigen (PCNA) (1:2000) from Chemicon (Temecula, CA); anti-Pax6 (1:2000) from Developmental Studies Hybridoma Bank (Iowa City, IA); anti-calbindin (1:3000) from Sigma; antiGFP (1:1000) from Invitrogen; anti- $\beta$-galactosidase (1:200) from Promega (Madison, WI); G10 anti-reelin (1:1000) from EMD Biosciences Calbiochem (San Diego, CA); and anti- $\beta$ III-tubulin (1:1000) from Covance (Princeton, NJ). Rat monoclonal antibody was anti-BrdU (1:200) from Harlan Sera-Lab (Loughborough, UK). Rabbit polyclonal antibodies were anti-GFP (1:500), anti-GluR2 $(2 \mathrm{ng} / \mu \mathrm{l})$, and anti-mGluR1 $\alpha(1$ : 400) from Chemicon; anti-calretinin (1:2000) was from Swant (Bellinzona, Switzerland); anti-Pax2 (1:750) was from Zymed (Invitrogen); anti-Tbr1 (1:2500) and anti-Tbr2 (1:2000) were from R.F.H.'s laboratory (Englund et al., 2005). Secondary antibodies (Alexa series; 1:200) were purchased from Invitrogen.

Microscopy and image processing. Epifluorescence and confocal imaging were done as described previously (Hevner et al., 2004; Englund et al., 2005). Digital images were optimized for brightness and contrast, outlines were traced, cells were counted, and areas were measured using Photoshop (Adobe Systems, San Jose, CA) and NIH ImageJ software as described previously (Hevner et al., 2004).

Cell counting in Math1 null cerebellum. Sagittal cryosections from Math1null and littermate control mouse embryos (E14.5, E16.5, and E19.5) were used for immunofluorescence to detect Pax6, Tbr2, and Pax2 as described above. For each transcription factor, the number of immunoreactive cells was counted manually in two cryosections through the vermis. Average cell
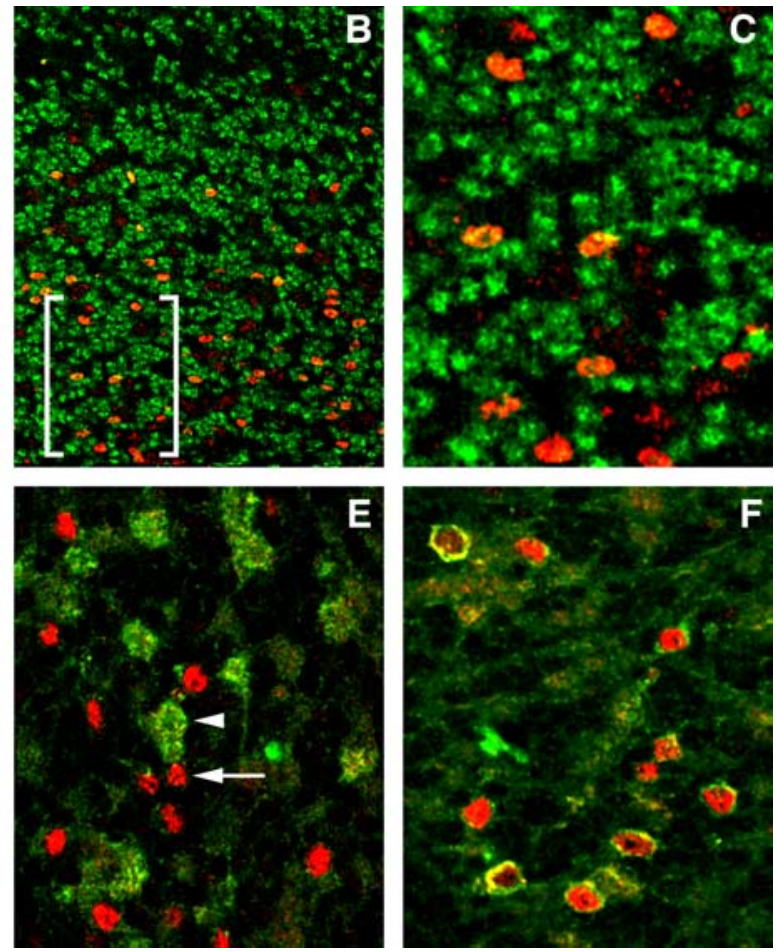

Figure 2. Tbr2 is specifically expressed by UBCs in adult mouse cerebellum. $A$, Tbr2 (red) and class III $\beta$-tubulin (green). All

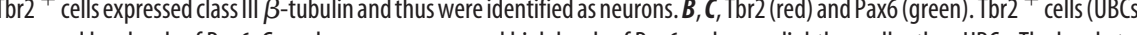
(arrow) were often adjacent to $\mathrm{mGluR1} \alpha^{+}$brushes (arrowhead), consistent with coexpression in the same cell. $\boldsymbol{F}$, Tbr2 (red) and GluR2 (green). GluR2 is a pan-UBC marker (Sekerková et al., 2004). Scale bar (in $\boldsymbol{A}$ ): $\boldsymbol{A}, \boldsymbol{C}, \boldsymbol{E}, \boldsymbol{F}, 20 \mu \mathrm{m} ; \boldsymbol{B}, 60 \mu \mathrm{m} ; \boldsymbol{D}, 13 \mu \mathrm{m}$.

counts per section were used for comparisons between control and Math1null mice.

Statistical analysis. Statistics and graphs were processed using Excel (Microsoft, Redmond, WA). Differences between groups were evaluated using Student's $t$ test (one-tailed).

\section{Results}

Tbr2 is a marker for UBCs in adult mouse cerebellum

A previous study showed that Tbr2 mRNA is expressed in the cerebellum and other brain regions during development (Bulfone et al., 1999). Using antibodies for immunofluorescence, we found that Tbr2 protein was detectable not only during development but also in the adult brain. In the adult cerebellum, Tbr2 protein was expressed in the nuclei of a subset of cells in the internal granular layer. The Tbr $2^{+}$cells were most abundant in lobule X (nodulus) and the ventral part of lobule IX (uvula) of the vermis (Fig. 1). An accumulation of Tbr ${ }^{+}$cells was also noted in lobules VI-VII (Fig. 1). Other lobules of the vermis, and the cerebellar hemispheres, contained few $\mathrm{Tbr}^{+}$cells. Numerous Tbr ${ }^{+}$cells were also present in the dorsal cochlear nucleus (data not shown). This distribution of Tbr $2^{+}$cells appeared to match that of UBCs, as described previously (Diño et al., 1999; Sekerková et al., 2004).

To determine whether Tbr2 is expressed by UBCs or other cell types in the internal granular layer, we tested for colocalization of Tbr2 with cell type-specific markers by double-labeling immunofluorescence. We found that all Tbr $2^{+}$cells expressed class III $\beta$-tubulin, which identified them as neurons (Fig. $2 A$ ). The internal granular layer contains three types of neurons: granule 

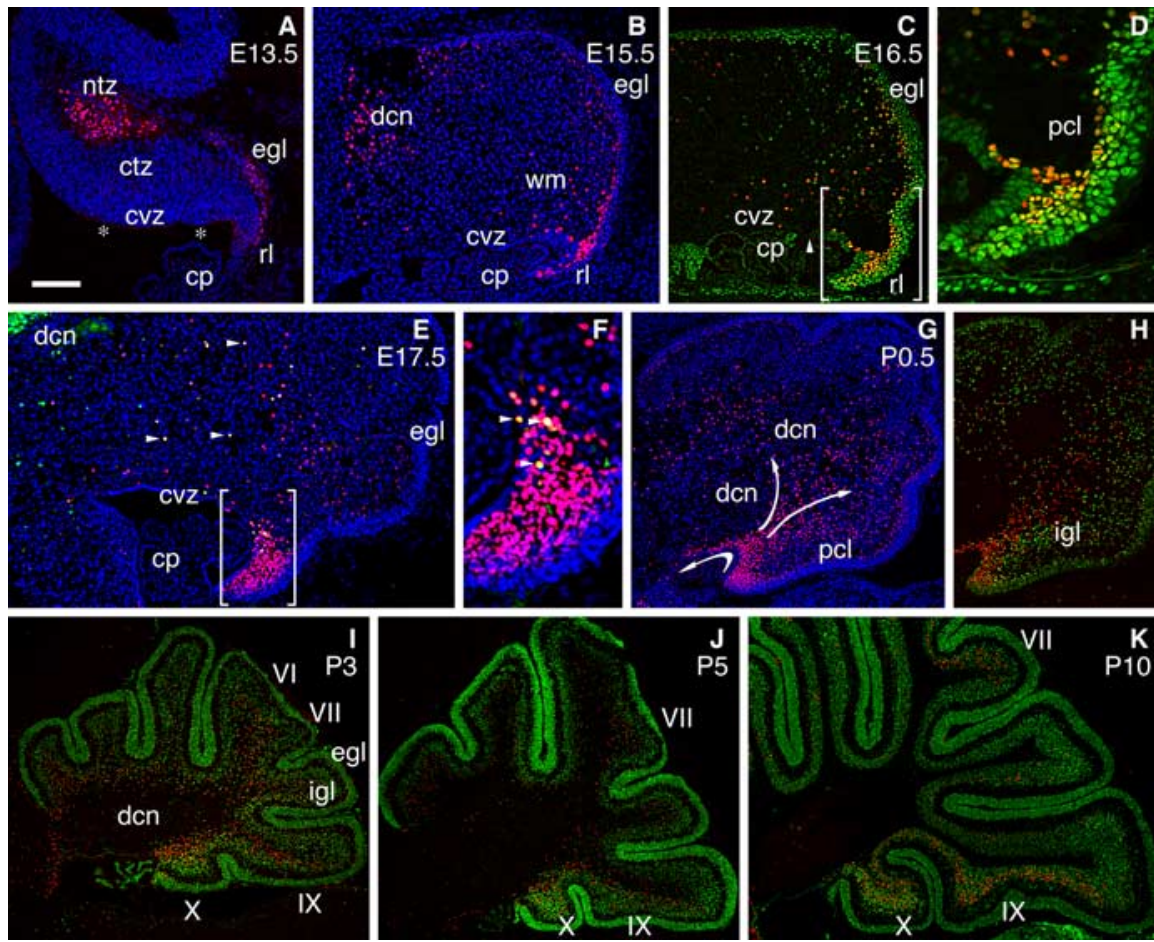

Figure 3. $\mathrm{Tbr}^{+}$cells in the developing cerebellum. $\boldsymbol{A}, \mathrm{Tbr2}$ (red) and DAPI (blue), E13.5. Tbr2 ${ }^{+}$cells were present in the nuclear transitory zone (ntz), external granular layer (egl), and rhombic lip ( $r l)$. Asterisks indicate edge artifact. cp, Choroid plexus; ctz, cortical transitory zone; cvz, cerebellar ventricular zone. $\boldsymbol{B}$, Tbr2 (red) and DAPI (blue), E15.5. Tbr2 ${ }^{+}$cells began streaming from the rhombic lip into the developing white matter (wm). Tbr2 was also expressed in the deep cerebellar nuclei (dcn), which develop from the nuclear transitory zone, and in the external granular layer. $\boldsymbol{C}, \boldsymbol{D}, \mathrm{Tbr} 2$ (red) and Pax6 (green), E16.5. Tbr2 and Pax6 were coexpressed by some cells in the core of the rhombic lip. Cells at the ventricular and subpial surfaces of the rhombic lip expressed only Pax6 and not Tbr2. Tbr2 ${ }^{+}$cells and Pax6 ${ }^{+}$cells avoided the developing Purkinje cell layer (pcl). Neither Pax6 nor Tbr2 was expressed in the cerebellar ventricular zone. However, Pax6 expression did extend a short distance rostral from the rhombic lip ( $\boldsymbol{C}$, arrowhead) and may have defined the boundary between progenitor compartments more accurately than morphological criteria. The bracketed area in $\boldsymbol{C}$ is shown at a higher magnification in $\boldsymbol{D}$. $\boldsymbol{E}, \boldsymbol{F}, \mathrm{Tbr2}$ (red), calretinin (green), and DAPI (blue), E17.5. Some Tbr2 ${ }^{+}$cells expressed calretinin in the developing white matter (E, arrowheads) and rhombic lip ( $\boldsymbol{F}$, arrowheads), suggesting that some UBCs differentiated as the calretinin ${ }^{+}$subtype before completing migration. Calretinin was also expressed by some projection neurons in the deep cerebellar nuclei (Fink et al., 2006). The bracketed area in $\boldsymbol{E}$ is shown at a higher magnification in $\boldsymbol{F}$. G, Tbr2 (red) and DAPI (blue), P0.5. Tbr2 ${ }^{+}$cells streamed out of the rhombic lip and into developing white matter, avoiding the Purkinje cell layer and the deep cerebellar nuclei. One pathway appeared to lead rostrally from the rhombic lip toward the brainstem (bottom arrow), whereas another pathway appeared to lead dorsally toward the cerebellar cortex (top arrows). $\boldsymbol{H}$, Tbr2 (red) and Pax6 (green), P0.5 (same section as $\boldsymbol{G}$ ). Migrating Tbr2 ${ }^{+}$cells avoided the developing internal granular layer (igl), marked by abundant Pax6 ${ }^{+}$cells. $\boldsymbol{I}-\boldsymbol{K}$, Tbr2 (red) and Pax6 (green), P3-P10. 0n P3 (I), most Tbr2 ${ }^{+}$UBCs were in the developing white matter. Many Tbr2 ${ }^{+}$UBCs reached the internal granular layer by P5 $(\boldsymbol{J})$, and most entered the internal granular layer by P10 $(\boldsymbol{K})$. Roman numerals indicate cerebellar lobules rich in Tbr2 ${ }^{+}$cells. Sagittal sections: rostral, left; dorsal, top. Scale bar (in $\boldsymbol{A}$ ): $\boldsymbol{A}-\boldsymbol{C}, \boldsymbol{E}, 100 \mu \mathrm{m} ; \boldsymbol{D}, \boldsymbol{F}, 40 \mu \mathrm{m} ; \boldsymbol{G}, \boldsymbol{H}, 150 \mu \mathrm{m} ; \boldsymbol{I}-\boldsymbol{K}, 200 \mu \mathrm{m}$.

neurons, GABAergic interneurons (including several subtypes), and UBCs. Pax6, considered as a marker of granule neurons (Engelkamp et al., 1999), was detected at low levels in Tbr2 ${ }^{+}$cells (Fig. $2 \mathrm{~B}, \mathrm{C}$ ). However, the majority of Pax $6^{+}$cells did not express Tbr2. GABA was not present in any Tbr ${ }^{+}$cells, indicating that they were not inhibitory interneurons (data not shown). Calreti$\mathrm{nin}^{+}$cells in the granular layer, which represent one subtype of UBCs (Nunzi et al., 2002), virtually always expressed Tbr2 $\left(97.3 \% ; 148 / 152\right.$ calretinin $^{+}$cells counted in sections sampling one adult half cerebellum), although not all Tbr2 ${ }^{+}$cells expressed calretinin (Fig. 2D). The other subtype of UBCs, identified by mGluR $1 \alpha$ immunoreactivity on dendritic brushes (Nunzi et al., 2002), typically showed mGluR $1 \alpha^{+}$brushes in close proximity to Tbr2 ${ }^{+}$cell nuclei (Fig. $2 E$ ). Because UBCs express mGluR $1 \alpha$ only on dendrites and not on cell bodies (Nunzi et al., 2002), the cellular coexpression of Tbr 2 in nuclei and mGluR $1 \alpha$ on dendrites could not be established definitively. In contrast,
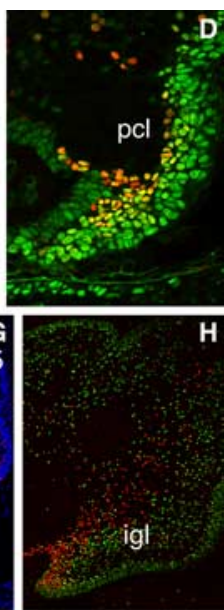

GluR2, a pan-UBC marker in lobule X and ventral lobule IX, is expressed throughout UBCs (Nunzi et al., 2002; Sekerková et al., 2004) and showed a 1:1 correlation with Tbr2 in these lobules (Fig. 2F). Together, these results showed that Tbr2 is a specific marker of both subtypes of UBCs in the adult cerebellum, and that UBCs express low levels of Pax6. Because Pax6 is a marker of cells derived from the rhombic lip during development (Engelkamp et al., 1999), the latter observation suggested that UBCs might originate from the rhombic lip.

\section{Tbr2 and the development of UBCs}

To study dynamics of Tbr2 expression in UBCs during development, we examined embryonic and postnatal brains. The first cells to express Tbr2, beginning on E12.5, were located in the nuclear transitory zone, which is the primordium of the deep cerebellar nuclei (Fig. 3A) (Fink et al., 2006). Tbr $2^{+}$cells were present in the nuclear transitory zone until E16.5. Beginning on E13.5, Tbr2 was also detected in the rhombic lip and the external granular layer (Fig. 3A). In the rhombic lip, Tbr2 was expressed in a subset of cells, many of them proliferating, until postnatal day 0.5 (P0.5), when the rhombic lip began to regress (Fig. $3 B-H$ ). Beginning on E15.5, Tbr2 was expressed in addition by cells dispersed in the developing white matter (Fig. 3B). Double labeling for Pax6 and Tbr2 demonstrated various degrees of coexpression within cells of the rhombic lip, external granular layer, and developing white matter (Fig. $3 C, D, H$ ). Within the rhombic lip, cells at the ventricular surface of the rhombic lip were mostly $\mathrm{Pax}^{+}{ }^{+}$/ Tbr2 ${ }^{-}$(Fig. 3D). In contrast, many cells in the core of the rhombic lip expressed Tbr2, often in combination with Pax6 (Fig. 3D). Cells in the external granular layer expressed Pax6 strongly but Tbr2 weakly or not at all (Fig. $3 B-K$ ). Within the external granular layer, Tbr2 was localized mainly in the internal sublamina.

In the developing white matter of late embryonic and neonatal mice, $\mathrm{Tbr}^{+}$cells appeared to form migration pathways leading from the rhombic lip dorsally through the developing white matter to the internal granular layer and rostrally toward the brainstem (Fig. $3 G$ ). The density of $\mathrm{Tbr} 2^{+}$cells in the white matter peaked on P0.5, when Tbr2 ${ }^{+}$cells appeared to exit the rhombic lip dorsally through a narrow channel between the ventricular zone and the cerebellar cortex and disperse in a fountain-like spray (Fig. 3G, top arrows). The $\mathrm{Tbr} 2^{+}$cells in white matter generally avoided the deep nuclei and the cerebellar cortex. Serial sections through the late embryonic cerebellum revealed that the rostrally directed pathway of $\mathrm{Tbr} 2^{+}$cells (toward brainstem) predominated in lateral regions of the cerebellar hemispheres, whereas the dorsally directed pathway (toward cerebellar cortex) predominated in medial regions (supplemental Fig. 1, available at 
www.jneurosci.org as supplemental material). Beginning on E17.5, a few Tbr $2^{+}$ cells in the rhombic lip and white matter expressed calretinin, suggesting that they were beginning to differentiate into the calretinin $^{+}$subtype of UBCs (Fig. $3 E, F$ ). During postnatal development from $\mathrm{P} 3$ to $\mathrm{P} 10, \mathrm{Tbr}^{+}$cells gradually moved from the white matter to the internal granular layer, where they settled in the typical distribution of UBCs (Fig. 3I-K). These findings suggested that UBCs are produced in the rhombic lip and migrate through immature white matter during late embryonic and early postnatal development.

Because the rhombic lip is a progenitor compartment, we surmised that some Tbr $2^{+}$cells in the rhombic lip might be mitotically active, like Tbr2 $2^{+}$"intermediate progenitor cells" in the developing cerebral cortex (Englund et al., 2005). Double immunofluorescence with markers of cell proliferation revealed that Tbr2 was expressed in a subset of mitotically active rhombic lip cells during the period of UBC neurogenesis (Fig. 4). Tbr2 was expressed during S-phase, as shown by acute BrdU administration (Fig. 4A), and during $\mathrm{M}$-phase, as observed in mitotic profiles (Fig. $4 A, B$ ). Also, some Tbr $2^{+}$cells in the rhombic lip expressed PCNA (Fig. 4D,E). Tbr $2^{+}$cells in the nuclear transitory zone, which is a postmitotic compartment, never expressed PCNA (Fig. 4C). By E19.5, most Tbr2 ${ }^{+}$cells in the rhombic lip did not express proliferation markers (Fig. $4 F$ ). Because Tbr2 expression in rhombic lip progenitor cells coincided with the period of UBC neurogenesis (Sekerková et al., 2004), our data supported the conclusion that the Tbr $2^{+}$rhombic lip progenitors produced UBCs.

\section{Cell birthdating analysis of $\mathrm{Tbr} 2^{+} \mathrm{UBC}$ migrations}

In rats, most UBCs are born from E16.5 to E22.5 (Sekerková et al., 2004), a period which corresponds to approximately E14.5 to E19.5 in mice. To study the neurogenesis and migration of Tbr2 ${ }^{+}$ UBCs in mice, we labeled embryos with BrdU on E15.5, E16.5, or E17.5 (the expected peak period of UBC neurogenesis), and then studied BrdU-labeled cells after survival to different ages.

Analysis of UBC cohorts at sequential ages from E18.5 to P10 supported the conclusion that Tbr ${ }^{+}$UBCs migrate through developing white matter. The migration of Tbr ${ }^{+} \mathrm{UBCs}$ born on E16.5 (Fig. 5A-D) exemplified several features, which were consistently seen with other cohorts as well. First, some newly generated $\mathrm{Tbr} 2{ }^{+} \mathrm{UBC}$ apparently remained in the rhombic lip for one or more days before migrating (Fig. 5A-D). This may account for the burst of $\mathrm{Tbr}^{+}$UBC migration from the rhombic lip observed at approximately P0.5 (Fig. $3 G$ ). Second, most Tbr2 ${ }^{+}$ UBCs entered the internal granular layer by $\mathrm{P} 10$, before granule cell neurogenesis was complete. Third, all cohorts migrated to the internal granular layer via the dorsal pathway from rhombic lip through immature white matter. Fourth, some Tbr ${ }^{+}$UBCs from each cohort migrated rostrally along the ventricular surface of the cerebellum to enter the cerebellar peduncles. This pathway may lead to the dorsal cochlear nucleus, which also contains Tbr2 ${ }^{+}$UBCs (Kalinichenko and Okhotin, 2005). Birthdating with survival to P19-P21 showed that UBC cohorts born on E15.5, E16.5, and E17.5 migrated to similar locations within the cerebellum (Fig. $5 E-G$ ). Cell counting indicated that $>50 \%$ of Tbr ${ }^{+}$UBCs were born from E15.5 to E17.5 in mice.

\section{Ablation of the rhombic lip reduces $\mathrm{Tbr} 2{ }^{+} \mathrm{UBC}$ production}

To test whether the rhombic lip is necessary for UBC production, we used an organotypic slice culture system, in which the rhombic lip was accessible to experimental manipulation. Sagittal slices of the cerebellum and brainstem (300 $\mu \mathrm{m}$ thick) were prepared from embryos on E14.5 ( $n=9$ control/ablation pairs) or E16.5 ( $n=5$ control/ablation pairs). Pairs of slices were matched for mediolateral position, and the rhombic lip was left intact (control) or removed with a scalpel (ablated) (Fig. 6A, D, G,J). Slices were cultured for 2-4 d in vitro (DIV) and then fixed, cryosectioned, and studied by immunofluorescence to detect Tbr2 and other cell type-specific markers. The markers included Pax6, a granule neuron marker (Engelkamp et al., 1999); Tbr1, a deep nuclei glutamatergic neuron marker (Fink et al., 2006); Pax2, a GABAergic interneuron marker (Maricich and Herrup, 1999); and calbindin, a Purkinje cell marker (Baimbridge and Miller, 1982; Ozol et al., 1999). Because deep nuclei glutamatergic neurons are produced before E14.5 (Miale and Sidman, 1961), and GABAergic interneurons and Purkinje cells are produced in the ventricular zone (Wang and Zoghbi, 2001; Hoshino et al., 2005), we expected that these cell types would not be affected by rhombic lip ablation on E14.5 or E16.5. 


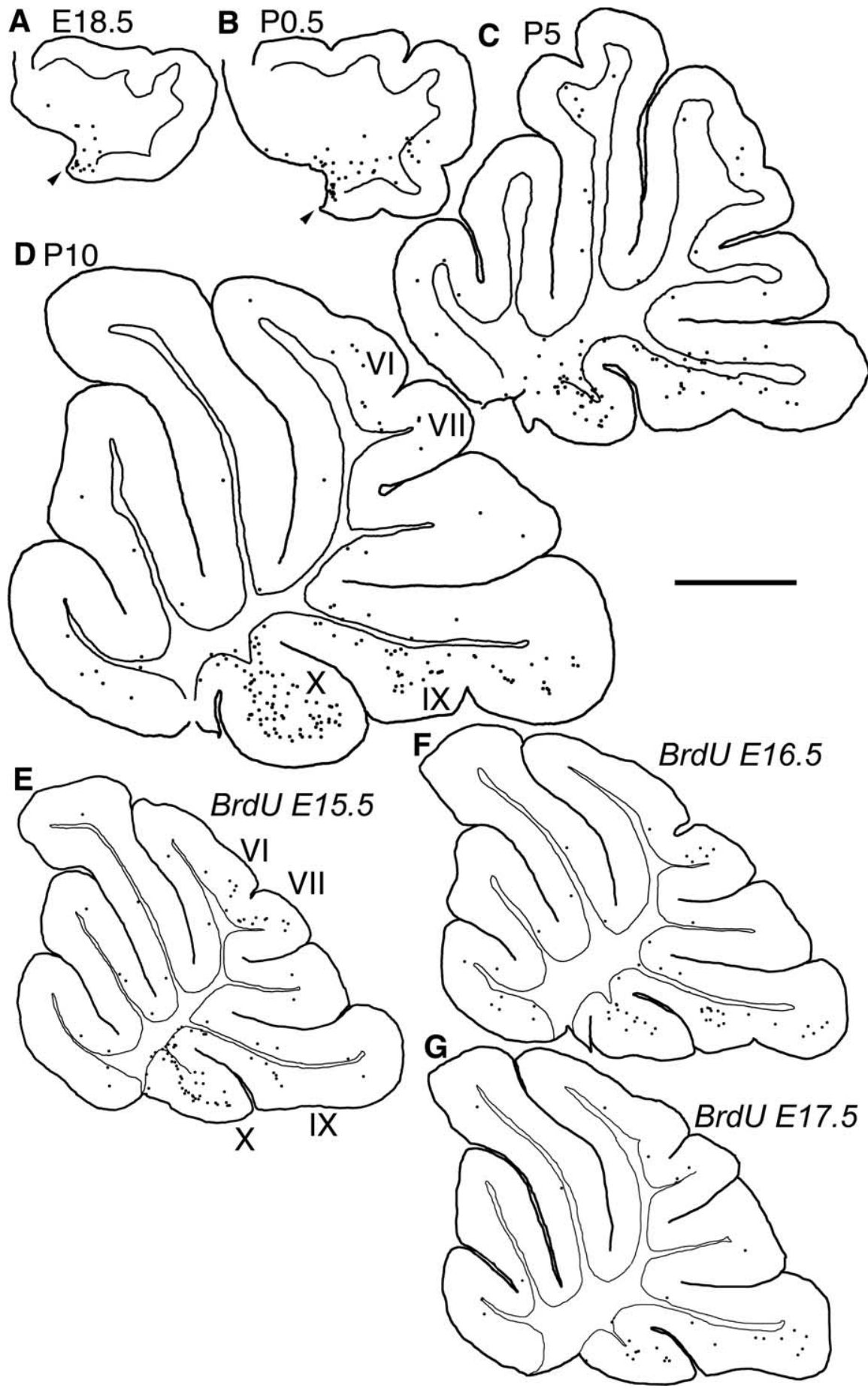

Figure 5. Migrations of Tbr2 ${ }^{+}$UBCs labeled with BrdU. $A-D$, Stages in the migration of Tbr2 ${ }^{+}$UBCs born on E16.5. The locations of double-labeled Tbr2 ${ }^{+} / \mathrm{BrdU}^{+}$cells (dots) were plotted after survival to E18.5 (A), P0.5 (B), P5 (C), and P10 (D) by tracing from digital images of sagittal sections (thick and thin lines as in Fig. 1). Many E16.5-born Tbr2 ${ }^{+}$cells remained in the rhombic lip until E18.5-P0.5 ( $\boldsymbol{A}, \boldsymbol{B}$, arrowheads). Most Tbr2 ${ }^{+}$UBCs entered the internal granular layer by P10. The number of E16.5-born Tbr2 ${ }^{+}$cells in the vermis appeared to increase postnatally, suggesting that some UBCs may have migrated from lateral to medial (supplemental Fig. 1, available at www.jneurosci.org as supplemental material). Steps in the migration of UBCs born on E15.5 and E17.5 (data not shown) were similar to those of E16.5-born UBCS. Roman numerals indicate lobules of the vermis with high density of Tbr2 ${ }^{+}$cells. Orientation: rostral, left; dorsal, top. $\boldsymbol{E}-\boldsymbol{G}$, Final distributions of Tbr2 ${ }^{+}$UBCs born on E15.5 (E), E16.5 $(\boldsymbol{F})$, and E17.5 (G). Pups were killed after survival to P19 $(\boldsymbol{E})$ or P21 $(\boldsymbol{F}, \boldsymbol{G})$. The locations of double-labeled, $\mathrm{Tbr}^{+} / \mathrm{BrdU}^{+}$cells (dots) were plotted as in $\mathbf{A - D}$. Tbr2 ${ }^{+}$UBCs born on E15.5, E16.5, and E17.5 showed similar overall distributions, with high abundance in lobule $X$ and ventral lobule IX, intermediate abundance in lobules $\mathrm{VI}-\mathrm{VII}$, and low abundance in other lobules. Orientation: rostral, left; dorsal, top. Scale bar: $A-D, 0.5 \mathrm{~mm} ; \boldsymbol{E}-\mathbf{G}, 1 \mathrm{~mm}$.
In control slices, the number and distribution of $\mathrm{Tbr}^{+}$cells appeared similar to normal development in vivo (Fig. $6 \mathrm{~A}-$ $C, G-I)$. The rhombic lip region appropriately expressed both Tbr2 and Pax6, and the external granular layer appropriately expressed Pax6 at high levels (Fig. $6 B, C, H, I)$. Control slices also showed normal expression of Tbr1, Pax2, and calbindin (data not shown). These findings in control slices demonstrated that key aspects of cerebellar development, including the production of different cell types, gene expression, and cell migration remained mostly intact under slice culture conditions.

Ablation of the rhombic lip led to a marked reduction of $\mathrm{Tbr} 2^{+}$cell density in the developing white matter (Fig. $6 D-F, J-$ $N)$. However, Tbr2 ${ }^{+}$cells were not completely depleted, presumably because some UBCs entered the developing white matter before the rhombic lip was ablated, and ablation may have been incomplete in some experiments. On average, the production of $\mathrm{Tbr} 2^{+}$cells was reduced by $51 \%$ after rhombic lip ablation in E14.5 slices $(p<0.05)$ and by $71 \%$ after rhombic lip ablation in E16.5 slices $(p<0.01)$ (Fig. $6 M$ ). Likewise, the external granular layer appeared to contain fewer $\operatorname{Pax}^{+}$ cells after rhombic lip ablation (Fig. $6 E, K)$. In contrast, Tbr1, Pax2, and calbindin cell densities were not significantly reduced after rhombic lip ablation. The sparing of Pax $2^{+}$interneurons (Fig. $6 \mathrm{~N}$ ) was particularly noteworthy, because these GABAergic cells are produced during the same time interval as $\mathrm{Tbr} 2{ }^{+} \mathrm{UBCs}$, but from the ventricular zone rather than the rhombic lip (Maricich and Herrup, 1999; Sekerková et al., 2004). These findings indicated that the rhombic lip is necessary on E14.5-E16.5 for the production of Tbr2 ${ }^{+}$UBCs and Pax6 ${ }^{+}$external granular cells but not for other cell types.

\section{Rhombic lip cells migrate into} developing cerebellar white matter and express Tbr2

Two explanations could account for the decreased production of $\mathrm{Tbr} 2{ }^{+}$UBCs after rhombic lip ablation. First, the rhombic lip could contain UBC progenitors, as suggested by coexpression of Tbr2 and proliferation markers (Fig. 4). Second, the rhombic lip could produce factors that stimulate UBC production outside the rhombic lip. To distinguish between these alternatives, we studied cerebellar slice cocultures, in which the ablated rhombic lip was replaced with tau-GFP transgenic rhombic lip from a littermate embryo (Fig. 7A). In these experiments $(n=18$; 

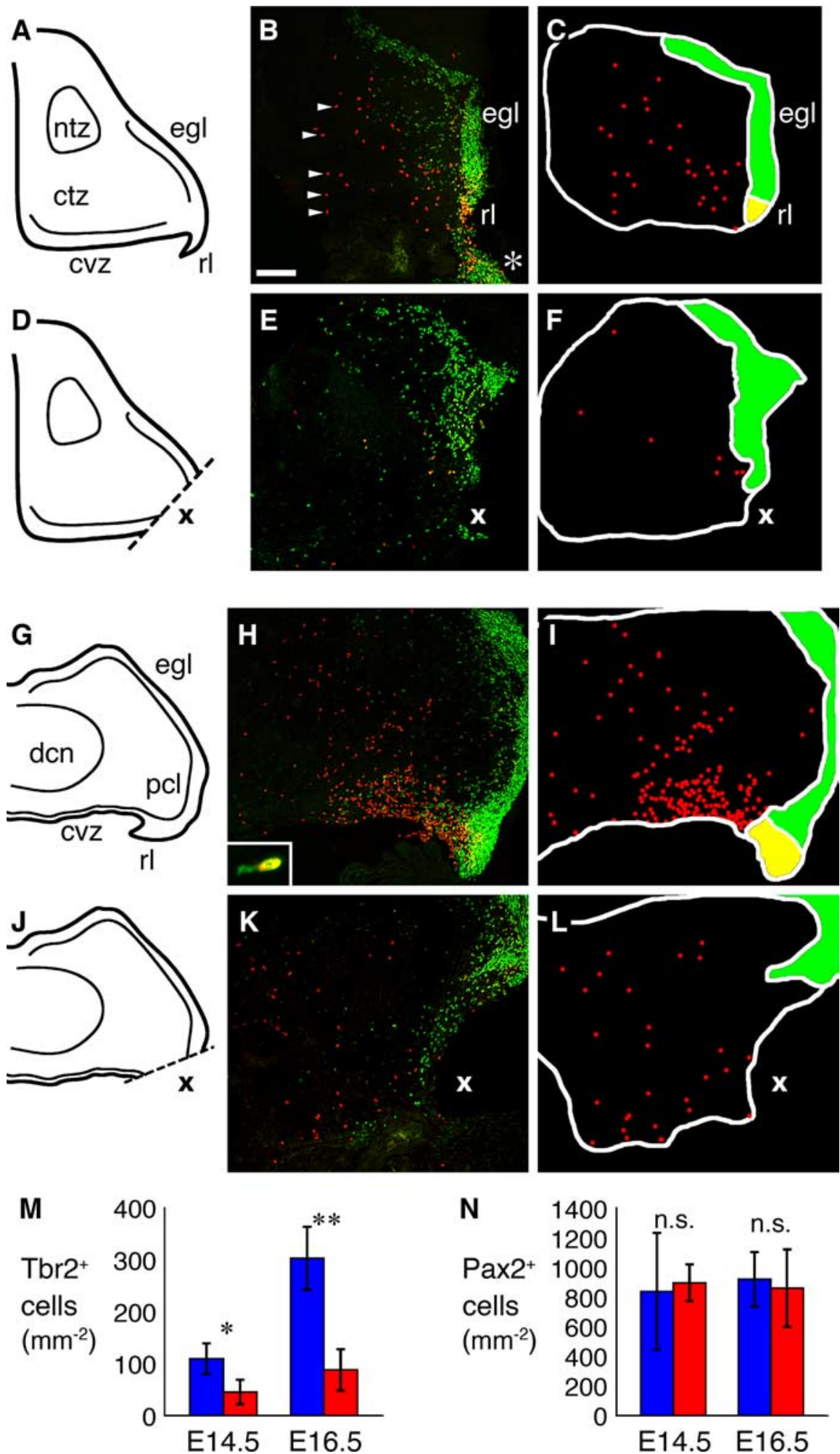

E13.5-E17.5), the tau-GFP transgenic rhombic lip explant fused with the nontransgenic cerebellar slice, allowing cells to migrate between the tissues.

After 2-4 DIV, tau-GFP ${ }^{+}$rhombic lip cells migrated into the developing white matter of the nontransgenic cerebellum and along the caudal edge corresponding to the external granular layer (Fig. $7 B-J$ ). These migrations appeared to follow the same pathways as observed in vivo. Significantly, tau-GFP ${ }^{+}$rhombic lip cells entered the developing white matter through a narrow channel and then dispersed widely, thus forming the same fountainlike spray of migrating UBCs as observed in normal development (compare Figs. $7 B$ and $3 G$ ). The tau-GFP ${ }^{+}$cells in developing white matter displayed leading processes typical of migrating neurons (Fig. $7 C, D, F)$, and they frequently expressed Tbr2 but not Pax2, Tbr1, or calbindin (Fig. 7B-J). Cell counting in sections from E16.5 and E17.5 sagittal slice cocultures $(n=10)$ showed that, on average, Tbr2 was expressed in $85.1 \pm 9.3 \%$ (mean \pm $\mathrm{SD})$ of tau-GFP ${ }^{+}$cells in developing white matter. Pax $2^{+}$cells accounted for most of the remaining fraction $(14.1 \pm 3.6 \%$ ) (Fig. $7 \mathrm{I}, \mathrm{J})$, suggesting that a portion of cerebellar ventricular zone was included with some rhombic lip explants. None of the migrating tau-GFP ${ }^{+}$cells expressed Tbr 1 or calbindin. Pax6 was strongly expressed by tau-GFP ${ }^{+}$cells in the external granular layer (Fig. $7 G$ ) but was only weakly expressed by tau-GFP ${ }^{+}$cells in the developing white matter (Fig. $7 H$ ). Coculture of slices cut in the coronal plane showed that $\mathrm{Tbr}^{+} /$tau-GFP $^{+}$rhombic lip cells migrated into the developing white matter at all mediolateral levels (supplemental Fig. 2, available at www.jneurosci.org as supplemental material). These coculture experiments demonstrated that the late embryonic rhombic lip produces abundant

(green) in control cerebellar slice, E16.5 plus 3 DIV, cryostat section $(\boldsymbol{E})$ and plot $(\boldsymbol{F})$. The inset in $\boldsymbol{H}$ shows Tbr2 (red) and calretinin (green) immunofluorescence in an adjacent cryosection, revealing typical UBC morphology. J, Diagram of E16.5 cerebellar slice after rhombic lip ablation $(x) . \boldsymbol{K}, \boldsymbol{L}, \mathrm{Tbr} 2$ (red) and Pax6 ( $g r e e n)$ in rhombic lip-ablated cerebellar slice, E16.5 plus 3 DIV, cryostat section $(\boldsymbol{K})$, and plot $(\boldsymbol{L})$. The number of $\mathrm{Tbr}^{+}{ }^{+}$cells in developing white matter was markedly reduced, compared with controls $(\boldsymbol{H}, \boldsymbol{I}) . \boldsymbol{M}, \boldsymbol{N}$, Areal density of $\mathrm{Tbr} 2^{+}$cells $(\boldsymbol{M})$ and Pax ${ }^{+}$cells $(\boldsymbol{N})$ in control (blue bars) and rhombic lip-ablated (red bars) slices after 3 DIV. The density of Tbr2 ${ }^{+}$cells (UBCs) decreased after rhombic lip ablation, but Pax $2^{+}$cells (GABAergic interneurons) were not affected. Data are mean \pm SD of $n=9$ (E14.5) or $n=5$ (E16.5) pairs of cultures. ${ }^{*} p<0.05$; ${ }^{* *} p<0.01$; n.S., not significant. Scale bar: $\boldsymbol{B}, \boldsymbol{E}, \boldsymbol{H}, \boldsymbol{K}, 100 \mu \mathrm{m} ; \boldsymbol{H}$, inset, $17 \mu \mathrm{m}$. 

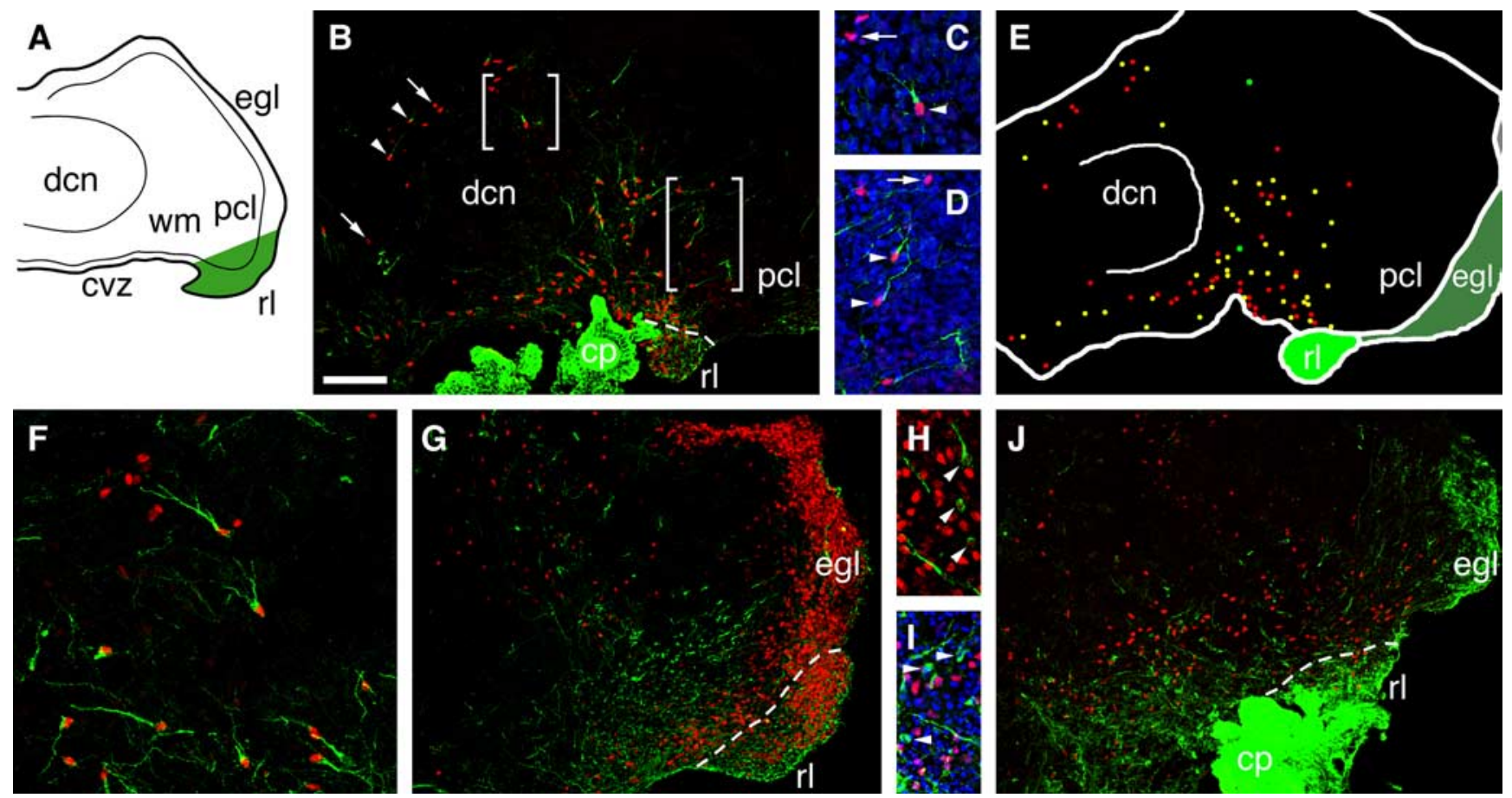

Figure 7. Cells migrate from rhombic lip explants into cerebellar white matter and express Tbr2 in organotypic slice coculture. A, Diagram showing placement of a tau-GFP transgenic rhombic lip (rl) explant (green) adjacent to a slice of E16.5 cerebellum from which the endogenous rhombic lip was removed. Abbreviations as in Figure 6G. $\boldsymbol{B}$, Tbr2 (red) and GFP (green) immunofluorescence in cryostat section through an E16.5 cerebellar slice and rhombic lip explant, cocultured for 4 DIV. Numerous tau-GFP ${ }^{+}$rhombic lip cells migrated into the developing white matter of the nontransgenic cerebellum. Most of the migrating cells expressed Tbr2 (arrowheads). The tau-GFP ${ }^{+} / \mathrm{Tbr}^{+}{ }^{+}$cells avoided the deep cerebellar nuclei, as did endogenous, nontransgenic tau-GFP ${ }^{-} /$ $\mathrm{Tbr2}^{+}$cells (arrows). The dashed line shows the boundary between tau-GFP transgenic rhombic lip and nontransgenic cerebellum. Choroid plexus (cp) was included with the rhombic lip explant and expressed tau-GFP. C, D, High-magnification views of bracketed regions in $\boldsymbol{B}$, counterstained with DAPI (blue). $\boldsymbol{E}$, Plot traced from section in $\boldsymbol{B}$, showing the positions of tau-GFP ${ }^{+} /$Tbr2 $^{+}{ }^{+}$cells (yellow dots), tau-GFP ${ }^{-} / \mathrm{Tbr2}^{+}$cells (red dots), and tau-GFP ${ }^{+} / \mathrm{Tbr} 2^{-}$cells (green dots). Only cells with visible nuclei (assessed from DAPI counterstain) were plotted. $\boldsymbol{F}$, Tbr2 (red) and GFP (green) immunofluorescence in another E16.5 cerebellar slice and rhombic lip explant, cocultured for 4 DIV. The migrating, tau-GFP ${ }^{+} / \mathrm{Tbr}^{+}{ }^{+}$cells displayed long processes, some of them branched. $\boldsymbol{G}, \boldsymbol{H}$, Pax6 (red) and GFP (green) immunofluorescence in cryosections of E16.5 cerebellar slice and explant cultured for 3 DIV (G) or 4 DIV (H). Pax6 ${ }^{+}$cells were located mainly in the external granular layer. Cells migrating through the developing white matter (tau-GFP ${ }^{+}$) expressed low levels of Pax6 ( $\boldsymbol{H}$, arrowheads). $\boldsymbol{I}, \boldsymbol{J}$, Pax2 (red) and GFP (green) immunofluorescence in E16.5 cerebellar slice and rhombic lip explant cultured for 4 DIV. Most tau-GFP ${ }^{+}$cells did not express Pax2 (I, arrowheads). The blue counterstain in I is DAPI. Scale bar (in $\left.\boldsymbol{B}\right): B, E, F, G, I, 100 \mu \mathrm{m} ; \boldsymbol{C}, \boldsymbol{D}, \boldsymbol{H}, \boldsymbol{J}, 50 \mu \mathrm{m}$.

$\mathrm{Tbr}^{+}$cells, which migrate directly into the developing cerebellar white matter in vitro. These findings provide strong support for the hypothesis that the rhombic lip is a principal source of UBCs in vivo.

\section{Math 1 is expressed by Tbr $2^{+}$progenitors and is required for UBC production}

Recent studies have identified Math1 expression as a molecular marker of the rhombic lip and its derivatives, including granule neurons and projection neurons of the deep cerebellar nuclei (Wang et al., 2005). To further determine whether Tbr $2^{+}$UBCs are derived from the rhombic lip, we tested for colocalization of Tbr2 and $\beta$-galactosidase expressed from the Math1 locus (Wang et al., 2005). We found that during the late embryonic period, $\mathrm{Tbr} 2^{+}$progenitors within the rhombic lip proliferative compartment exhibited diffuse cytoplasmic $\beta$-galactosidase immunoreactivity, suggestive of active Math1 gene expression (Fig. $8 A-C$ ). In addition, most $\mathrm{Tbr} 2^{+}$cells in the rhombic lip and migrating away from it contained one or more dots of cytoplasmic $\beta$-galactosidase immunoreactivity (Fig. $8 B, C$, arrowheads). These dots are thought to represent perdurance of the $\beta$-galactosidase protein after active gene expression (Stühmer et al., 2002). The presence of $\beta$-galactosidase immunoreactivity in Tbr $2^{+}$progenitors and migrating cells supported the conclusion that UBCs originate from the rhombic lip.

Functionally, the Math1 gene appears to be essential for the neurogenesis of rhombic lip derivatives, including granule neurons and deep nuclei projection neurons (Ben-Arie et al., 1997; Wang et al., 2005). This suggested that Math1 might also be important for the neurogenesis of UBCs. To investigate this possibility, we studied Tbr2 expression in Math1-null mice, which have a small, malformed cerebellum (Wang et al., 2005). Because these mice die at birth, we could study them only during embryonic and prenatal periods. We found that the number of Tbr ${ }^{+}$ UBC precursors was severely reduced in Math1-null embryos relative to controls on E14.5 (83\% decrease), E16.5 (92\% decrease) (Fig. 8D,E), and E19.5 (90\% decrease) (Fig. $8 H, I)$. Pax $6^{+}$granule neuron progenitors were also profoundly reduced ( $>99 \%$ decrease on E14.5, E16.5, and E19.5), with only rare groups of $\mathrm{Pax}^{+}{ }^{+}$cells in the external granular layer of Math1-null mice (Fig. $8 E$, arrows). In contrast, Pax $2^{+}$inhibitory interneurons and progenitors, which are derived from the cerebellar ventricular zone (Maricich and Herrup, 1999; Hoshino et al., 2005), were relatively preserved in Math1-null mice. The number of Pax ${ }^{+}$cells was actually slightly increased relative to controls on E14.5 (13\% increase) but was slightly reduced on E16.5 (16\% decrease) (Fig. 8F, G) and further reduced on E19.5 (24\% decrease) (Fig. $8 \mathrm{~J}, \mathrm{~K}$ ). These results suggest that the neurogenesis of $\mathrm{Tbr}^{+}$UBCs and $\mathrm{Pax}^{+}$granule neurons are highly Math1dependent, and that the survival of $\operatorname{Pax} 2^{+}$inhibitory interneurons may depend in part on interactions with rhombic lip derivatives. 

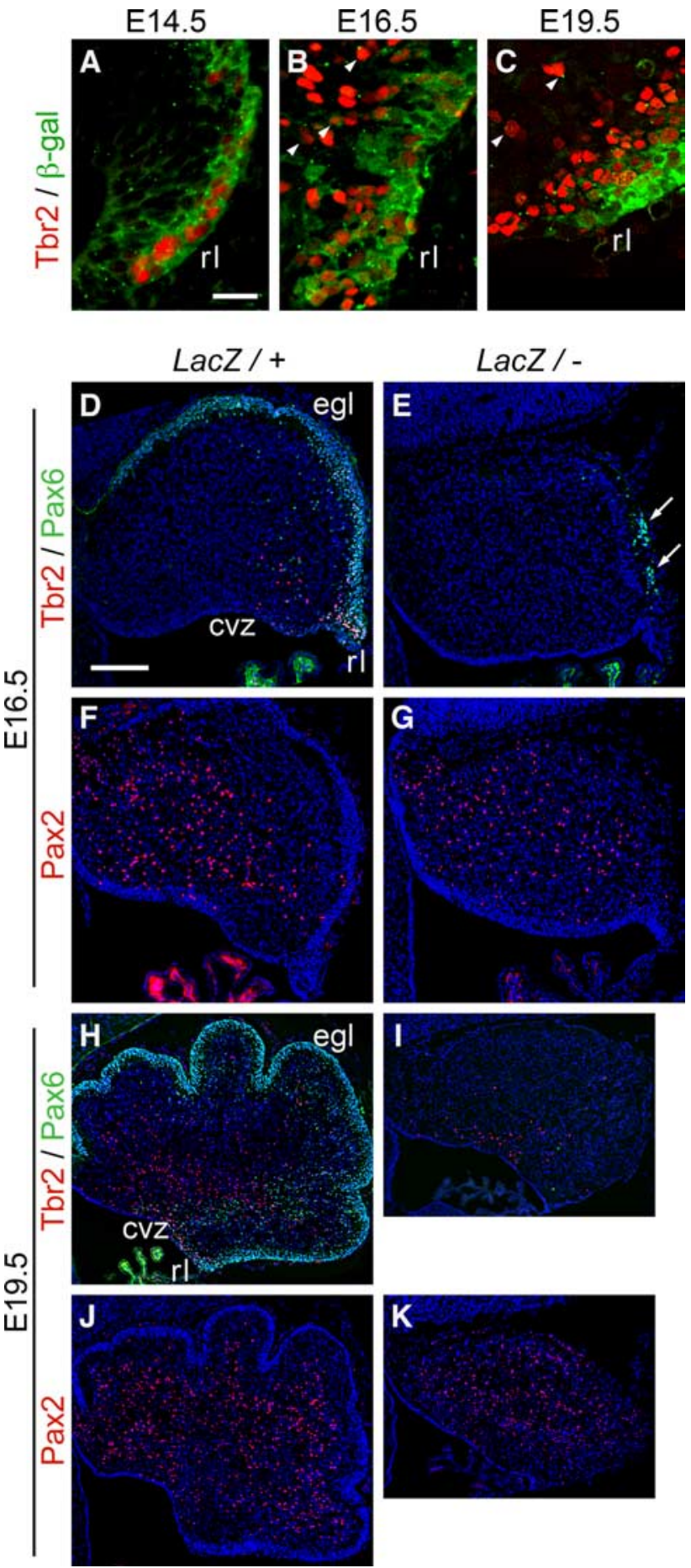

Figure 8. Math 1 is required for the production of Tbr2 ${ }^{+} \mathrm{UBCS} . A-C$, Math 1 gene expression, indicated by $\beta$-galactosidase (green) immunoreactivity, was detected in Tbr2 ${ }^{+}$cells (red) on E14.5 (A), E16.5 (B), and E19.5 (C). Many Tbr2 ${ }^{+}$progenitors exhibited diffuse cytoplasmic $\beta$-galactosidase immunoreactivity, suggestive of active Math1 gene expression. In contrast, $\mathrm{Tbr2}^{+}$cells migrating out of the rhombic lip contained a cytoplasmic dot of $\beta$-galactosidase immunoreactivity ( $\boldsymbol{B}, \boldsymbol{C}$, arrowheads), consistent with perdurance after active gene expression. $\boldsymbol{D}-\boldsymbol{K}$, Rhombic lip (rI)-derived cell types were selectively reduced in Math1-null (LacZ/-) cerebellum $(\boldsymbol{E}, \boldsymbol{G}, \boldsymbol{I}, \boldsymbol{K})$ compared with the Math1 heterozygous $(\operatorname{LacZ} /+)$ controls $(\boldsymbol{D}, \boldsymbol{F}, \boldsymbol{H}, \boldsymbol{J})$ on E16.5 (D-G) and E19.5 (H-K). Double immunofluorescence for Tbr2 (red) and Pax6 (green) (D, $\boldsymbol{E}, \boldsymbol{H}, \boldsymbol{I})$ revealed a severe reduction of $\mathrm{Tbr} 2^{+} \mathrm{UBCs}$ and $\mathrm{Pax}^{+}{ }^{+}$granule cell progenitors in Math1-null cerebellum. The arrows in $E$ indicate small clusters of $\mathrm{Pax}^{+}$cells in the rudimentary external granular layer (egl). Pax2 ${ }^{+}$cells (red) $(\boldsymbol{F}, \boldsymbol{G}, \boldsymbol{J}, \boldsymbol{K})$, which are GABAergic interneurons derived from the cerebellar ventricular zone (cvz), were relatively spared. See text for cell counting results. Other abbreviations as in previous figures. The blue fluorescence $(\boldsymbol{D}-\boldsymbol{K})$ is DAPI. Scale bars: (in $\boldsymbol{A}) \boldsymbol{A}-\mathbf{C}, 20 \mu \mathrm{m}$; (in $\boldsymbol{D}) \boldsymbol{D}-\mathbf{G}, 100 \mu \mathrm{m} ; \boldsymbol{H}-\boldsymbol{K}, 200 \mu \mathrm{m}$.
$\mathrm{Tbr}^{+} \mathrm{UBCs}$ are ectopically positioned near the rhombic lip in reeler mutant cerebellum

The cerebellum in reeler mutant mice is small and disorganized, caused by deficiency of reelin, an extracellular signaling protein (Rice and Curran, 2001). A recent study of adult reeler mice found that UBCs were numerically reduced (by $\sim 40 \%$ for the calretinin $^{+}$subset) and were ectopically located in the ependyma, white matter, and posterior deep cell clusters (Ilijic et al., 2005). Based on their findings in reeler, the authors suggested that UBCs originate from the cerebellar ventricular zone (Ilijic et al., 2005).

To further investigate the role of reelin signaling and implications for UBC cell origins and migrations, we used Tbr2 as a marker in reeler cerebellum. First, we used double labeling to test whether reelin is expressed by Tbr ${ }^{+}$UBCs. We found that reelin was expressed transiently by migrating $\mathrm{Tbr} 2{ }^{+} \mathrm{UBC}$ during the late embryonic period (Fig. 9A). Second, we studied the distribution of Tbr ${ }^{+}$UBCs in the postnatal reeler cerebellum. In P0.5 reeler mice, Tbr2 ${ }^{+}$UBCs accumulated near the rhombic lip in large numbers, and few cells migrated dorsally toward the cerebellar cortex (Fig. 9B; compare with Fig. 3G). In P22 reeler cerebellum, Tbr $2^{+}$UBCs remained most abundant in the caudoventral sector, near the regressed rhombic lip (Fig. 9C). The number of $\mathrm{Tbr} 2{ }^{+}$UBCs was apparently reduced relative to age-matched controls (data not shown), confirming the previous report (Ilijic et al., 2005). Double labeling to detect Pax6 revealed that many Tbr $2^{+}$UBCs were isolated in the cerebellar white matter, away from Pax $6^{+}$granule neurons (Fig. 9D). These findings suggested that UBC migration and integration into cerebellar circuitry were impaired in reeler. Moreover, the accumulation of UBCs in caudal sectors of the reeler cerebellum was consistent with our hypothesis that UBCs arise from the rhombic lip, although another interpretation has been suggested (Ilijic et al., 2005).

\section{Discussion}

UBCs are a unique type of glutamatergic interneurons that play an important role in vestibulo-cerebellar circuitry (for review, see Kalinichenko and Okhotin, 2005). Although many properties of UBCs have been characterized previously, their developmental origins remained unknown. Here, we used Tbr2 as a marker to trace UBC origins to the rhombic lip, and we demonstrated that the rhombic lip is necessary for UBC production. Our conclusions were further confirmed by demonstrating that UBC progenitors express Pax6 and Math1, molecular markers of the rhombic lip (Engelkamp et al., 1999; Wang et al., 2005). Our studies also revealed novel pathways used by UBCs to migrate through developing cerebellar white matter.

\section{Neurogenesis, migration, and differentiation of UBCs}

UBCs are produced during the late embryonic and perinatal periods in mice and rats (Fig. 5) (Sekerková et al., 2004). The rhombic lip appears to be the sole site of UBC neurogenesis, because it is the only location where Tbr $2^{+}$cells incorporated BrdU (Fig. $4 A$ ), passed through M-phase (Fig. $4 B$ ), and expressed PCNA (Fig. $4 D, E$ ). Tbr $^{+}$cells showed no proliferative activity in the external granular layer or the developing white matter, where granule neurons and $\mathrm{Pax} 2{ }^{+}$GABAergic interneurons are produced, respectively (Miale and Sidman, 1961; Zhang and Goldman, 1996; Maricich and Herrup, 1999). UBC fate commitment and subtype specification probably also occur in the rhombic lip, either during or immediately after neurogenesis. This was inferred, because some Tbr $2{ }^{+}$UBC precursors expressed calretinin within the rhombic lip and developing white matter (Fig. 3E,F). 

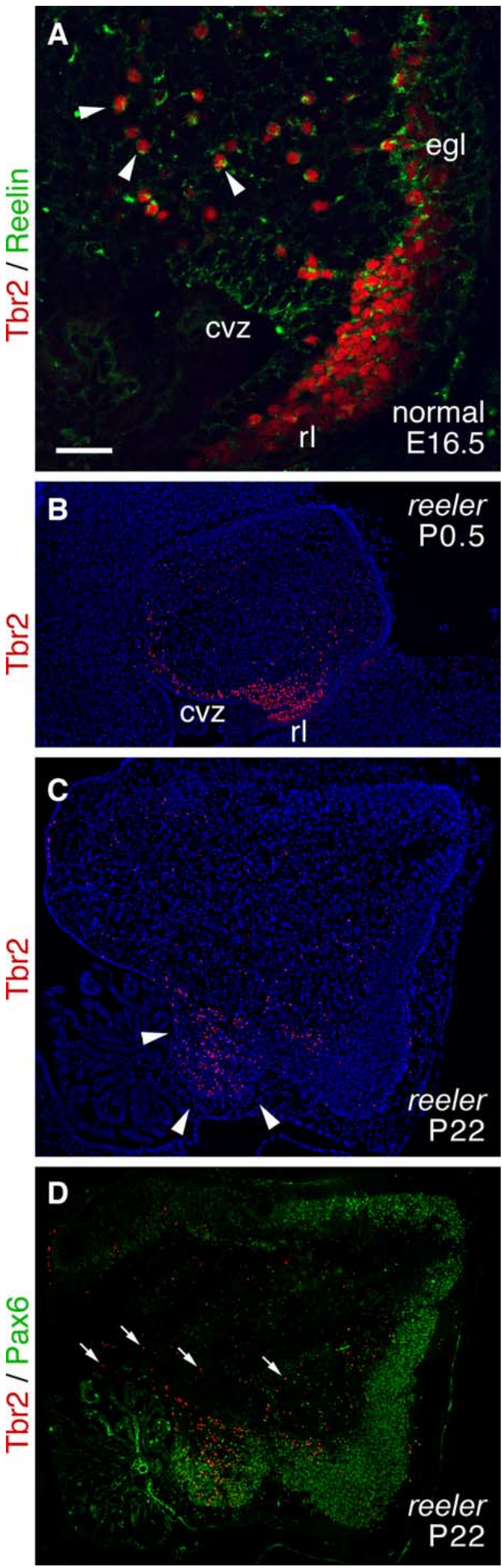

Tbr2 was also expressed (weakly) in the internal sublamina of the external granular layer (Fig. $3 B, D$ ), but because this is a postmitotic compartment for granule neuron differentiation (Engelkamp et al., 1999), we believe that these cells were granule neuron precursors.

After neurogenesis, most UBCs appear to traverse a novel pathway to the internal granular layer. First, UBCs exit the rhombic lip via a short, narrow channel between the developing cerebellar cortex and the ventricular zone (Fig. 3G). This channel leads to the developing white matter, where UBCs disperse widely and proceed to the internal granular layer. Most UBCs appeared to reach the internal granular layer by P10 (Fig. 5), where they continue to mature throughout the first postnatal month (Morin et al., 2001). In addition, many Tbr2 ${ }^{+}$UBCs appear to migrate rostrally along the ventricular zone toward the brainstem (Fig. $3 E, G, I$ ) (supplemental Fig. 1, available at www.jneurosci.org as supplemental material), presumably to enter cochlear nuclei, another major location of UBCs (Kalinichenko and Okhotin, 2005).

\section{Transcription factors in the development of UBCs}

Transcription factors Math1, Pax6, and Tbr2 may be part of a transcription factor cascade expressed in the development of UBCs and other glutamatergic, rhombic lip-derived neurons (Hevner et al., 2006). All three transcription factors are expressed at least transiently in the development of UBCs, as well as deep nuclei projection neurons and granule neurons (Figs. 2-4, 8) (Engelkamp et al., 1999; Machold and Fishell, 2005; Wang et al., 2005; Fink et al., 2006). In contrast, these transcription factors are never expressed in cerebellar GABAergic neuron lineages (Purkinje cells and inhibitory interneurons). Math1 appears to be critical for the neurogenesis of UBCs, granule neurons, and deep nuclei projection neurons (Fig. 8) (Ben-Arie et al., 1997; Wang et al., 2005). A few Tbr $2^{+}$UBCs and Pax6 ${ }^{+}$granule cell precursors were produced in Math1 null mice (Fig. 8), suggesting that some degree of compensation or functional redundancy with Math1 is present within rhombic lip lineages. Alternatively, a small minority of glutamatergic neurons might be derived from a separate pool of Math1 ${ }^{-}$progenitors, perhaps located in the caudal ventricular zone. Pax6 is important for granule cell differentiation, migration, and neurite extension (Engelkamp et al., 1999; Swanson et al., 2005), but its functions in UBC development are unknown. The functional role of Tbr2 in cerebellar development has not been studied. Some cholinergic neurons in the brainstem are also produced from Math $1^{+}$progenitors in the rhombic lip, but their possible expression of Pax6 and Tbr2 has not been evaluated (Machold and Fishell, 2005; Wang et al., 2005).

The finding that UBCs, deep nuclei projection neurons, and

\section{$\leftarrow$}

Figure 9. $\mathrm{Tbr2}^{+} \mathrm{UBC}$, reelin expression, and abnormal migrations in reeler. $A$, Tbr2 (red) and reelin (green) immunofluorescence, E16.5 cerebellum. Many Tbr2 ${ }^{+}$UBCs expressed reelin (arrowheads) after exiting the rhombic lip (rl). cvz, Cerebellar ventricular zone. B, Tbr2 (red) immunofluorescence and DAPI counterstain (blue), reeler cerebellum, P0.5. Tbr2 ${ }^{+} \mathrm{UBC}$ s were abundant near the rhombic lip (rl), suggesting their migration was impaired. Few Tbr2 ${ }^{+} \mathrm{UBCS}$ migrated dorsally through developing white matter compared with controls (see Fig. 3G). The rostral pathway along the cerebellar ventricular zone (cvz) appeared relatively preserved. C, Tbr2 (red) immunofluorescence and DAPI (blue), reeler cerebellum, P22. The number of Tbr2 ${ }^{+}$ UBCs was overall reduced, compared with age-matched controls (data not shown) (for comparison with P10, see Fig. 5D) (llijic et al., 2005). Nevertheless, Tbr2 ${ }^{+}$UBCs were most abundant in the caudoventral sector (arrowheads), corresponding to lobules IX and X.D, Tbr2 (red) and Pax6 (green) immunofluorescence, reeler cerebellum, P22 (same section as C). Many Tbr2 ${ }^{+} \mathrm{UBCs}$ were abnormally isolated from $\mathrm{Pax}^{+}$granule neurons (arrows), suggesting they did not integrate into cerebellar circuitry (sagittal sections). Orientation: dorsal, top; rostral, left. Scale bar (in $A$ ): $A, 30 \mu \mathrm{m} ; \boldsymbol{B}-\boldsymbol{D}, 200 \mu \mathrm{m}$. 
granule neurons all arise from Math $1^{+}$progenitors in the rhombic lip suggests that they derive from the same lineages. Clonal analyses in laac $Z$ transgenic mice indicated that granule neuron and deep nuclei lineages separate early in cerebellar development (Mathis et al., 1997; Mathis and Nicolas, 2003). However, those studies did not evaluate molecular markers in the clonal cells; thus, there was some uncertainty in their identification of cell types. Rhombic lip lineages may be complex, because deep nuclei projection neurons, UBCs, and granule neurons are produced sequentially in development, and because some lineages (especially granule neuron progenitors) are amplified after branching off from the shared lineage. In future studies, it may be more productive to study lineages in vitro, applying molecular markers to evaluate daughter cell phenotypes. Recently, this approach was used to characterize cerebral cortex progenitor lineages (Shen et al., 2006).

As in the cerebellum, Pax6 and Tbr2 also play important roles in the development of glutamatergic (but not GABAergic) neurons in the cerebral cortex. Pax6 and Tbr2 are expressed sequentially in the production of many, possibly all, glutamatergic cortical neurons (Englund et al., 2005; Hevner, 2006). Pax6 appears to control a binary choice between glutamatergic and GABAergic fates during neurogenesis of upper neocortical layers (Schuurmans et al., 2004). Tbr2 functions in cortical development are unclear. Germline inactivation of the Tbr2/Eomes gene results in early embryonic lethality before brain development (Russ et al., 2000).

\section{Compartmentalization of cerebellar neurogenesis}

The cerebellum contains five major types of neurons, which use either glutamate (deep nuclei projection neurons, granule neurons, and UBCs) or GABA (Purkinje cells and inhibitory interneurons) as neurotransmitter. The embryonic sources of all five types have now been defined. All three glutamatergic types come from the rhombic lip (Machold and Fishell, 2005; Wang et al., 2005; Fink et al., 2006; our study), whereas both GABAergic types come from the cerebellar ventricular zone (Maricich and Herrup, 1999; Hoshino et al., 2005). Thus, cerebellar neurogenesis is apparently compartmentalized according to neurotransmitter type at progenitor stages, before any neurons are produced. Interestingly, a similar compartmentalization of neurogenesis occurs in the developing forebrain. GABAergic interneurons are produced in the basal telencephalon, and glutamatergic projection neurons are produced in the dorsal telencephalon (for review, see Marín and Rubenstein, 2001; Schuurmans and Guillemot, 2002). Compartmentalization in the forebrain is thought to be mediated by the expression of different combinations of transcription factor genes (Schuurmans and Guillemot, 2002). The same is evidently true in the cerebellum. Pax6, Tbr2, and Math1 are expressed in the rhombic lip (Engelkamp et al., 1999; Wang et al., 2005; our study), whereas Ptfla (like Math1, a basic-helix-loop-helix transcription factor gene) is expressed in the cerebellar ventricular zone (Hoshino et al., 2005). Math1 is necessary for the production of all three types of glutamatergic cerebellar neurons (BenArie et al., 1997; Wang et al., 2005; our study), whereas Ptfla is necessary for the production of both types of GABAergic cerebellar neurons (Hoshino et al., 2005).

\section{Defining the rhombic lip}

Our studies support the recent hypothesis that Math1 gene expression is a defining molecular characteristic of the rhombic lip (Wang et al., 2005). In addition, we have shown that all three glutamatergic cerebellar neuron types come from Pax $6{ }^{+}$progen- itors (Fink et al., 2006; our study), confirming that Pax6 is likewise a marker for rhombic lip lineages (Engelkamp et al., 1999). The gene expression patterns suggest that the rhombic lip progenitor compartment extends slightly beyond the classical morphological boundaries of the rhombic lip. Both Math1 and Pax6 expression were observed in the posterior margin of the cerebellar ventricular zone (Figs. 3C,D, $8 \mathrm{~A}$ ). Thus, the rhombic lip progenitor pool (defined molecularly) includes cells that would morphologically be included with the posterior margin of the ventricular zone. A similar distinction has been drawn in the forebrain, where gene expression studies revealed that the cortical neuroepithelium extends a short distance into the lateral ganglionic eminence, which appears morphologically to be part of the basal telencephalon (Schuurmans and Guillemot, 2002).

\section{UBC migrations in reeler}

UBCs, like other cells from the rhombic lip, transiently express reelin protein (Fig. 9A) (Miyata et al., 1996; Fink et al., 2006). Furthermore, reelin is necessary for UBC migrations, as indicated by the accumulation of UBCs near the rhombic lip in P0.5 reeler cerebellum (Fig. 9B), and by their ectopic positions in the mature reeler cerebellum (Fig. 9C,D) (Ilijic et al., 2005). Previously, this finding has been interpreted to suggest that UBCs arise from the ventricular zone (Ilijic et al., 2005). However, with our additional studies presented here, a new interpretation is possible. We suggest that UBC migrations were slowed or arrested in reeler at points along the dorsal and rostral pathways of UBC migration from the rhombic lip. Thus, the reeler phenotype fits with the model of neurogenesis and migration that we have proposed here.

\section{References}

Abbott LC, Jacobowitz DM (1995) Development of calretininimmunoreactive unipolar brush-like cells and an afferent pathway to the embryonic and early postnatal mouse cerebellum. Anat Embryol 191:541-559.

Altman J, Bayer SA (1977) Time of origin and distribution of a new cell type in the rat cerebellar cortex. Exp Brain Res 29:265-274.

Anderson SA, Qiu M, Bulfone A, Eisenstat DD, Meneses J, Pedersen R, Rubenstein JLR (1997) Mutations of the homeobox genes $D l x-1$ and Dlx-2 disrupt the striatal subventricular zone and differentiation of late born striatal neurons. Neuron 19:27-37.

Baimbridge KG, Miller JJ (1982) Immunohistochemical localization of calcium-binding protein in the cerebellum, hippocampal formation and olfactory bulb of the rat. Brain Res 245:223-229.

Ben-Arie N, Bellen HJ, Armstrong DL, McCall AE, Gordadze PR, Guo Q, Matzuk MM, Zoghbi HY (1997) Math1 is essential for genesis of cerebellar granule neurons. Nature 390:169-172.

Bulfone A, Martinez S, Marigo V, Campanella M, Basile A, Quaderi N, Gattuso C, Rubenstein JLR, Ballabio A (1999) Expression pattern of the Tbr2 (Eomesodermin) gene during mouse and chick brain development. Mech Dev 84:133-138.

Diño MR, Willard FH, Mugnaini E (1999) Distribution of unipolar brush cells and other calretinin immunoreactive components in the mammalian cerebellar cortex. J Neurocytol 28:99-123.

Engelkamp D, Rashbass P, Seawright A, van Heyningen V (1999) Role of Pax6 in development of the cerebellar system. Development 126:3585-3596.

Englund C, Fink A, Lau C, Pham D, Daza RA, Bulfone A, Kowalczyk T, Hevner RF (2005) Pax6, Tbr2, and Tbr1 are expressed sequentially by radial glia, interposed progenitor cells, and postmitotic neurons in developing neocortex. J Neurosci 25:247-251.

Fink AJ, Englund C, Daza RAM, Pham D, Lau C, Nivison M, Kowalczyk T, Hevner RF (2006) Development of the deep cerebellar nuclei: transcription factors and cell migration from the rhombic lip. J Neurosci 26:3066-3076

Harris J, Moreno S, Shaw G, Mugnaini E (1993) Unusual neurofilament 
composition in cerebellar unipolar brush neurons. J Neurocytol 22:1039-1059.

Hevner RF (2006) From radial glia to pyramidal-projection neuron: transcription factor cascades in cerebral cortex development. Mol Neurobiol 33:33-50.

Hevner RF, Daza RAM, Englund C, Kohtz J, Fink A (2004) Postnatal shifts of interneuron position in the neocortex of normal and reeler mice: evidence for inward radial migration. Neuroscience 124:605-618.

Hevner RF, Hodge RD, Daza RAM, Englund C (2006) Transcription factors in glutamatergic neurogenesis: conserved programs in neocortex, cerebellum, and adult hippocampus. Neurosci Res 55:223-233.

Hoshino M, Nakamura S, Mori K, Kawauchi T, Terao M, Nishimura YV, Fukuda A, Fuse T, Matsuo N, Sone M, Watanabe M, Bito H, Terashima T, Wright CVE, Kawaguchi Y, Kakao K, Nabeshima Y (2005) Ptf1a, a bHLH transcriptional gene, defines GABAergic neuronal fates in cerebellum. Neuron 47:201-213.

Ilijic E, Guidotti A, Mugnaini E (2005) Moving up or moving down? Malpositioned cerebellar unipolar brush cells in reeler mouse. Neuroscience 136:633-647.

Kalinichenko SG, Okhotin VE (2005) Unipolar brush cells-a new type of excitatory interneuron in the cerebellar cortex and cochlear nuclei of the brainstem. Neurosci Behav Physiol 35:21-36.

Machold R, Fishell G (2005) Math1 is expressed in temporally discrete pools of cerebellar rhombic-lip neural progenitors. Neuron 48:17-24.

Maricich SM, Herrup K (1999) Pax-2 expression defines a subset of GABAergic interneurons and their precursors in the developing murine cerebellum. J Neurobiol 41:281-294.

Marín O, Rubenstein JLR (2001) A long, remarkable journey: tangential migration in the telencephalon. Nat Rev Neurosci 2:780-790.

Mathis L, Nicolas J-F (2003) Progressive restriction of cell fates in relation to neuroepithelial cell mingling in the mouse cerebellum. Dev Biol 258:20-31

Mathis L, Bonnerot C, Puelles L, Nicolas J-F (1997) Retrospective clonal analysis of the cerebellum using genetic laacZ/lacZ mouse mosaics. Development 124:4089-4104.

Miale IL, Sidman RL (1961) An autoradiographic analysis of histogenesis in the mouse cerebellum. Exp Neurol 4:277-296.

Miyata T, Nakajima K, Aruga J, Takahashi S, Ikenaka K, Mikoshiba K, Ogawa M (1996) Distribution of a reeler gene-related antigen in the developing cerebellum: an immunohistochemical study with an allogeneic antibody CR-50 on normal and reeler mice. J Comp Neurol 372:215-228.

Morin F, Diño MR, Mugnaini E (2001) Postnatal differentiation of unipolar brush cells and mossy fiber-unipolar brush cell synapses in rat cerebellum. Neuroscience 104:1127-1139.

Mugnaini E, Floris A (1994) The unipolar brush cell: a neglected neuron of the mammalian cerebellar cortex. J Comp Neurol 339:174-180.
Nunzi MG, Birnstiel S, Bhattacharyya BJ, Slater NT, Mugnaini E (2001) Unipolar brush cells form a glutamatergic projection system within the mouse cerebellar cortex. J Comp Neurol 434:329-341.

Nunzi M-G, Shigemoto R, Mugnaini E (2002) Differential expression of calretinin and metabotropic glutamate receptor $\mathrm{mGluR} 1 \alpha$ defines subsets of unipolar brush cells in mouse cerebellum. J Comp Neurol 451:189-199.

Ozol K, Hayden JM, Oberdick J, Hawkes R (1999) Transverse zones in the vermis of the mouse cerebellum. J Comp Neurol 412:95-111.

Pratt T, Sharp L, Nichols J, Price DJ, Mason JO (2000) Embryonic stem cells and transgenic mice ubiquitously expressing a tau-tagged green fluorescent protein. Dev Biol 228:19-28.

Rice DS, Curran T (2001) Role of the reelin signaling pathway in central nervous system development. Annu Rev Neurosci 24:1005-1039.

Russ AP, Wattler S, Colledge WH, Aparicio SAJR, Carlton MBL, Pearce JJ, Barton SC, Surani MA, Ryan K, Nehls MC, Wilson V, Evans MJ (2000) Eomesodermin is required for mouse trophoblast development and mesoderm formation. Nature 404:95-99.

Schuurmans C, Guillemot F (2002) Molecular mechanisms underlying cell fate specification in the developing telencephalon. Curr Opin Neurobiol $12: 26-34$

Schuurmans C, Armant O, Nieto M, Stenman JM, Britz O, Klenin N, Brown C, Langevin L-M, Seibt J, Tang H, Cunningham JM, Dyck R, Walsh C, Campbell K, Polleux F, Guillemot F (2004) Sequential phases of cortical specification involve Neurogenin-dependent and -independent pathways. EMBO J 23:2892-2902.

Sekerková G, Ilijic E, Mugnaini E (2004) Time of origin of unipolar brush cells in the rat cerebellum as observed by prenatal bromodeoxyuridine labeling. Neuroscience 127:845-858.

Shen Q, Wang Y, Dimos JT, Fasano CA, Phoenix TN, Lemischka IR, Ivanova NB, Stifani S, Morrisey EE, Temple S (2006) The timing of cortical neurogenesis is encoded within lineages of individual progenitor cells. Nat Neurosci 9:743-751.

Stühmer T, Puelles L, Ekker M, Rubenstein JLR (2002) Expression from a Dlx gene enhancer marks adult mouse cortical GABAergic neurons. Cereb Cortex 12:75-85.

Swanson DJ, Tong Y, Goldowitz D (2005) Disruption of cerebellar granule cell development in the Pax6 mutant, Sey mouse. Brain Res Dev Brain Res 160:176-193.

Wang VY, Zoghbi HY (2001) Genetic regulation of cerebellar development. Nat Rev Neurosci 2:484-491.

Wang VY, Rose MF, Zoghbi HY (2005) Math1 expression redefines the rhombic lip derivatives and reveals novel lineages within the brainstem and cerebellum. Neuron 48:31-43.

Zhang L, Goldman JE (1996) Generation of cerebellar interneurons from dividing progenitors in white matter. Neuron 16:47-54. 